\title{
Analysis of Surface Sound Duct in the Northern Shelf of the South China Sea
}

\author{
Ke Qu $\mathbb{D}^{1,2,3,4}$ Shengchun Piao ${ }^{\mathbb{D}},{ }^{1,3}$ Jianbo Zhou, ${ }^{1,3}$ and Fengqin $\mathrm{Zhu}^{4}$ \\ ${ }^{1}$ College of Underwater Acoustic Engineering, Harbin Engineering University, Harbin 150001, China \\ ${ }^{2}$ Guangdong Province Key Laboratory for Coastal Ocean Variation and Disaster Prediction, Guangdong Ocean University, \\ Zhanjiang 524088, China \\ ${ }^{3}$ Acoustic Science and Technology Laboratory, Harbin Engineering University, Harbin 150001, China \\ ${ }^{4}$ College of Electronics and Information Engineering, Guangdong Ocean University, Zhanjiang 524088, China
}

Correspondence should be addressed to Shengchun Piao; piaoshengchun@hrbeu.edu.cn

Received 4 January 2018; Accepted 31 March 2018; Published 7 May 2018

Academic Editor: Tony Murmu

Copyright (C) $2018 \mathrm{Ke}$ Qu et al. This is an open access article distributed under the Creative Commons Attribution License, which permits unrestricted use, distribution, and reproduction in any medium, provided the original work is properly cited.

\begin{abstract}
The northern shelf of the South China Sea (NSSCS) is characterized by surface low-salinity water due to discharge from the Pearl River. In such an environment, the surface sound duct (SSD) is the most important duct for near-surface sonar applications. Nevertheless, the mechanism of SSD formation is very complicated and is influenced by salinity, temperature at the air-sea interface, and various additional marine phenomena. In this study, an 8-year conductivity-temperature-depth (CTD) profile of the NSSCS was used to analyze the SSD formation. An advanced diagrammatic method is proposed to provide a quantitative analysis of the contribution of salinity, temperature, and hydrostatic pressure on SSD formation. Large salinity gradient $(0.25 \mathrm{psu} / \mathrm{m})$ was shown to play a crucial role in SSD formation when a mixed layer exists. As representative examples, the sea under cold surges, typhoon genesis, and low-salinity lenses were studied. Conversely, the absence of SSDs in low-salinity water was also observed in upwelling regions. This study further showed that highly negative temperature gradients affect SSD formation even in low-salinity water. Furthermore, although the duct depth of a low-salinity SSD is usually less than 10 meters, it still can serve as an effective duct for acoustic propagation.
\end{abstract}

\section{Introduction}

The principal characteristic of a surface sound duct (SSD) is that the sound speed increases monotonically with the depth below the sea surface. This upward-refractive sound speed structure acts as a duct in which acoustic energy may be trapped and propagated to long ranges without bottom interaction. In continental shelf regions, the seafloor is a lossy boundary and hence the SSD is an effective duct for the sound propagation over a long range.

Variability in water temperature, salinity, and hydrostatic pressure affects SSD formation through the structure of sound speed. In general, water temperature and pressure are considered to dynamically vary with depth and have a strong influence on sound speed structure. On the contrary, salinity remains relatively constant over ocean zones and thus has little effect on sound speed [1]. A well-known example is the hydrostatic duct, which exists in the mixed layer and is caused by hydrostatic pressure. It also exhibits distinct variations yearly due to seasonal fluctuations in water temperature [2]. However, the effect of salinity on duct formation is not negligible in the freshening process, that is, when freshwater mixes with seawater due to river discharge into the sea.

The freshening process is primarily controlled by several factors including local freshwater flux, river discharge, and salt transport by large-scale circulation or oceanic eddies [3]. In the freshening area, the upper water column has low salinity and a strong salinity gradient, meaning that salinity may influence sound propagation. The acoustic propagation experiments in low-salinity water, conducted on the west coast of Canada [4] and the Baltic Sea [5], verified that the SSD behaved like an acoustic waveguide with optimum duct propagation. Those experimental results can be well explained by theoretical studies [6-10]. However, this work 
focused on sound transmission and did not provide an indepth analysis of the causal link between the freshening process and the SSD. Bulgakov et al. studied the mechanism responsible for the SSD in the tropical Atlantic Ocean. This area contains a strong freshening of oceanic waters by continental discharge and rainfall. As a result, these studies were able to distinguish the "haline duct" from the hydrostatic duct $[11,12]$. Since the mixed layer in the tropical ocean is relatively stable, temperature contributes little, and as such, the formation of the haline duct was due to a sharp change in salinity. It was then pointed out by Kim et al. that the mechanism of the haline duct formation is comprehensive for the middle ocean latitude; even in a very strong salinity gradient environment, the haline duct is not formed [13]. A temperature-salinity gradient diagram ( $T-S$ diagram) method was developed to analyze the formation of the SSD [14]. This approach combines various factors to determine whether an SSD exists. However, real CTD profiles may be interpreted improperly by the $T$-S diagram. This is because there are many points of inflection, or drastic slope changes, in the fine sampled CTD profiles. Hence, a more effective method is needed to give a quantitative analysis of SSD formation.

In this paper, an advanced diagram tool is proposed. The first improvement is that the new method can be applied to fine sampled data, such as the CTD. The second improvement focuses on distinguishing the general contributing factors of the different types of SSDs by valuating the contribution of salinity, temperature, and pressure. This improved diagram tool was used to study the SSD in the northern shelf of the South China Sea (NSSCS), and the quantitative characteristics of the duct are discussed. The NSSCS is characterized by seasonally varying precipitation [15] and influx of freshwater from the Pearl River [16-18]. The structure of the temperature and salinity is very complicated in this area and depends on many factors, such as geography, monsoon, circulation, upwelling, and the Kuroshio. Many acousticians and oceanographers have investigated the sound speed profile near the sea surface $[19,20]$, but the effect of salinity on duct formation has not been previously investigated. A quantitative analysis of the SSD formation in the NSSCS is presented here.

\section{Data and Statistical Analysis}

2.1. Presentation of the Data. The northern South China Sea annual open cruise is a long-term investigation program that has been conducted every autumn since 1992. The open cruise is carried out by the South China Sea Institute of Oceanology, Chinese Academy of Sciences. To understand the physical, chemical, and biological aspects of the northern South China Sea, measurements included water mass property, ocean circulation, atmospheric structure, and chemical and biological elements [21, 22]. For this study, three sections outside the Pearl River estuary were selected. Figure 1 shows the shipboard CTD measurement sites. There were a total of 108 quality controlled CTD profiles after 8 years (2004-2011) of field investigation cruises. These profiles are sufficient to provide a general outline of the freshening process in

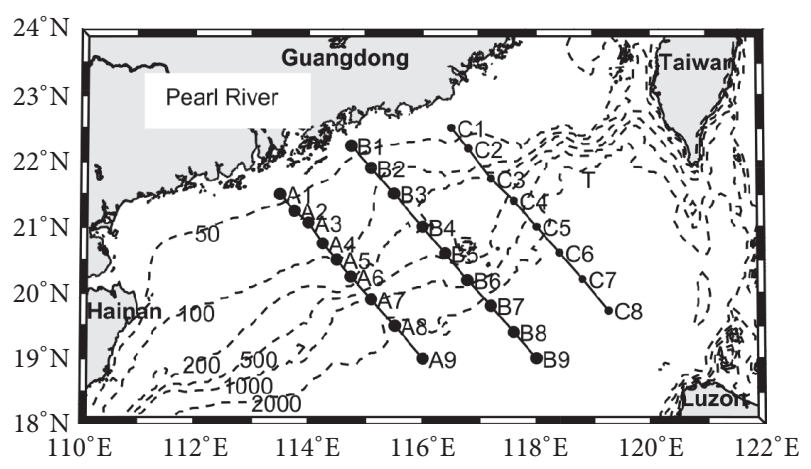

FIGURE 1: Spatial distribution of shipboard CTD observations during the open cruises. Some sites were not measured in each year due to the actual investigation plan and in some cases bad weather conditions.

the NSSCS during the autumn. Sample CTD profiles were consistently obtained every $1 \mathrm{~m}$ in depth and the sound speed profiles were computed using Medwin's formula [23].

2.2. Statistical Analysis. According to the actual salinity of the NSSCS, low-salinity water contains salinity lower than 32 psu [24]. Table 1 shows the results for 8 years at the sites in Figure 1. It is well known that a low-salinity region located outside the Pearl River estuary has spread along the continental shelf. Due to the Coriolis force and the Ekman effect of the northeast monsoon in autumn, the offshore expansion of the Pearl River diluted water is constrained and westward [25]. The occurrence proportion of the low-salinity water is relatively low at some sites that are far from the estuary, or on the east side of the estuary. According to statistical analysis, almost all of the low-salinity environment was present in the SSD (98.4\%), and duct formation was observed 40 times in the 43 cases of normal salinity investigated. Among all of the 108 measurements, the duct formed 104 times (96.2\%). The probability of waveguides formation was higher than $31.1 \%$, which was observed in the East China Sea [14]. In this case, the isothermal layer was shown to be more stable in lower sea latitudes. The $1 \mathrm{~m}$ sample data in the present study represent the waveguides of a few meters in depth, which was omitted in the $10 \mathrm{~m}$ sample from the East China Sea dataset. Among all of the 104 ducts, there were 41 ducts less than $10 \mathrm{~m}$. This means that a fine sampled profile can better reflect the character of the SSD.

All of the CTD profiles are referred to as Cases I-IV. As shown in Table 1, only 4 cases of no SSD formation were observed. It can be shown that SSD is ubiquitous in the NSSCS. Considering that low-salinity water is helpful in SSD formation and the spatial distributions of low-salinity water, it can be concluded that the occurrence probability of SSD is relatively high at some sites that are near the estuary, or on the west side of the estuary.

Four typical examples are plotted in Figure 2, where the columns from left to right are temperature, salinity, and sound speed. The first row refers to the low-salinity environments. Case I was measured at site A3 $\left(20^{\circ} 59^{\prime} \mathrm{N}\right.$, $114^{\circ} 0^{\prime} \mathrm{E}$ ) on September 10, 2011, and Case II was measured 

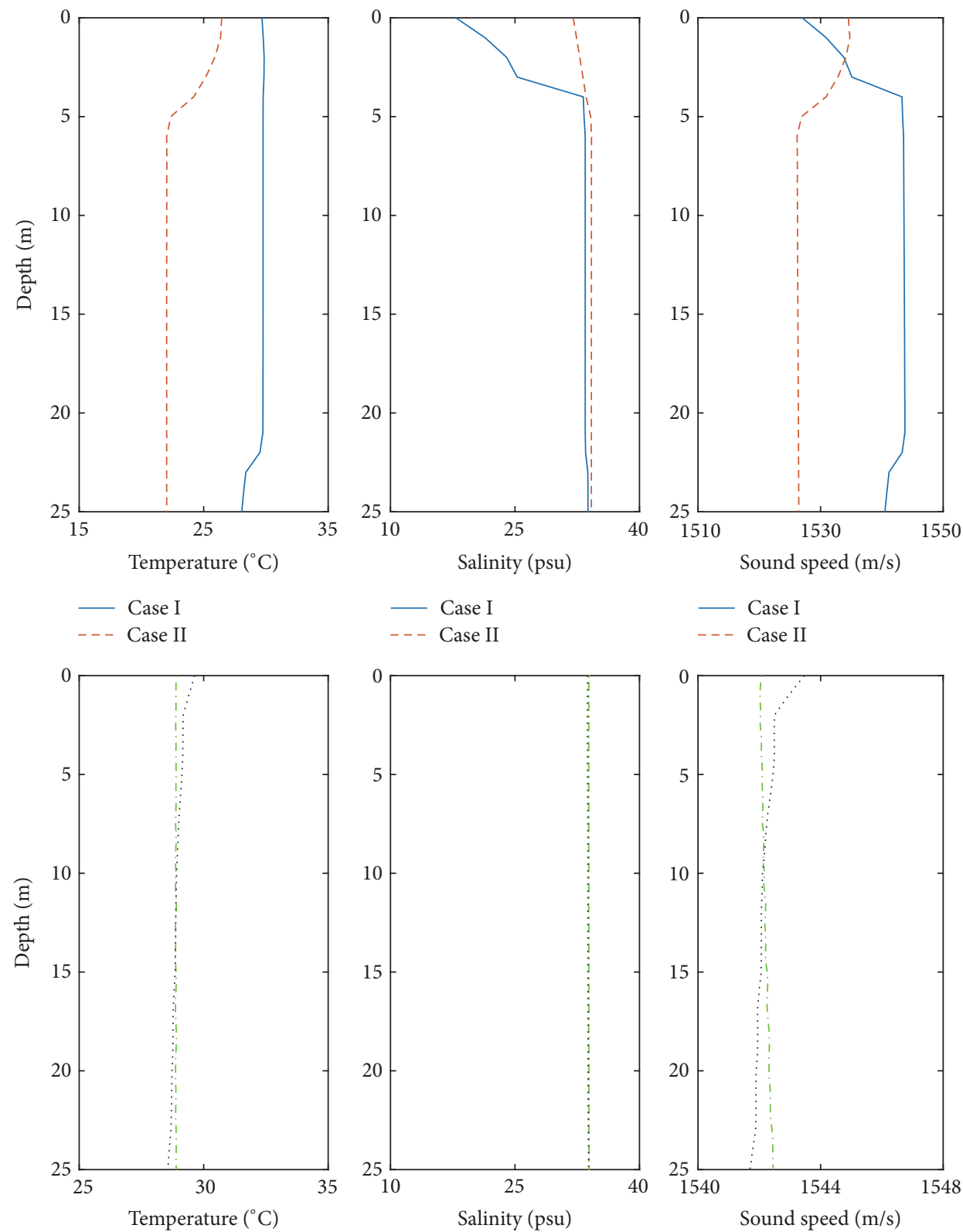

$\begin{array}{ll}\cdots & \text { Case III } \\ \ldots . . & \text { Case IV }\end{array}$
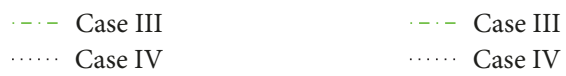

..... Case IV

Figure 2: Typical cases in the NSSCS.

TABLE 1: Occurrence statistics of SSD formation and freshening process in the 8-year open cruise.

\begin{tabular}{lccc}
\hline & A1-A9 & B1-B9 & C1-C9 \\
\hline Normal salinity/low salinity & $16 / 27$ & $11 / 22$ & $16 / 16$ \\
Duct formation in low salinity (Case I) & 27 & 22 & 15 \\
No duct formation in low salinity (Case II) & 0 & 0 & 1 \\
Duct formation in normal salinity (Case III) & 15 & 11 & 14 \\
No duct formation in low salinity (Case IV) & 1 & 0 & 2 \\
\hline
\end{tabular}

at site $\mathrm{Cl}\left(22^{\circ} 41^{\prime} \mathrm{N}, 116^{\circ} 17^{\prime} \mathrm{E}\right)$ on August 16, 2008. Cases I and II represent duct formation and no duct formation in low-salinity environments, respectively. The bottom row represents the normal salinity environment. The duct was present in Case III; however, no duct was formed in Case IV. CTD profiles were measured at $\mathrm{C} 4\left(21^{\circ} 23^{\prime} \mathrm{N}, 117^{\circ} 36^{\prime} \mathrm{E}\right)$ on September 8, 2005, and $\mathrm{C} 1\left(22^{\circ} 11^{\prime} \mathrm{N}, 116^{\circ} 48^{\prime} \mathrm{E}\right)$ on September 2 , 2004. These data show that salinity was an important factor for duct formation in the freshening process, but not the exclusive factor. Additionally, under the influence of various 
factors, the characteristics of the SSD showed significant variability, similar to that observed in the gradient of sound speed.

Accordingly, the aim of the following experiment was to provide an analysis of the relationship between the SSD and the temperature-salinity structure in the NSSCS and to explore the response of the duct to some oceanographic phenomena.

\section{Analysis on the Formation of SSD}

3.1. An Improved T-S Gradient Method. The formation and characteristics of SSD are the combined product of temperature, salinity, and hydrostatic pressure. To assess the contributions of these different factors, an improved $T-S$ gradient method will be provided as follows.

The sound speed $c(z)$ as a function of the depth coordinate, $z$, is given by Medwin's formula:

$$
\begin{aligned}
c(T, S, z)= & 1449.2+4.6 T-0.055 T^{2}+0.00029 T^{3} \\
& +(1.34-0.01 T)(S-35)+0.016 z,
\end{aligned}
$$

where $T$ is the temperature and $S$ is the salinity. In an SSD, the medium is upward refracting, meaning the gradient of sound speed $d c / d z>0$. Taking into account the factors in duct formation, the complete form can be written as

$$
\frac{d c}{d z}=\frac{\partial c}{\partial T} \frac{\partial T}{\partial z}+\frac{\partial c}{\partial S} \frac{\partial S}{\partial z}+\frac{\partial c}{\partial z}>0
$$

Substituting (1) into (2) yields an expression for the SSD formation:

$$
\frac{d c}{d z}=\beta T_{z}+\gamma S_{z}+0.016>0
$$

where

$$
\begin{aligned}
& \beta=4.95-0.11 T+0.00087 T^{2}-0.01 S, \\
& \gamma=1.34-0.01 T .
\end{aligned}
$$

As shown in (3), temperature gradient $T_{z}$, salinity gradient $S_{z}$, and pressure gradient (constant value) lead to the vertical variability of sound speed. The effect of salinity in (4) is much smaller than that of a constant and temperature; that is to say, the last term in (4) can be disregarded. $\beta$ and $\gamma$, which serve as the weight coefficient of $T_{z}$ and $S_{z}$, respectively, depend only on temperature.

The corresponding critical $S_{z}$, necessary in SSD formation, is

$$
S_{z}=-\frac{\beta(T(z))}{\gamma(T(z))} T_{z}-\frac{0.016}{\gamma(T(z))} .
$$

The straight-line equation of $S_{z}$ above becomes a threshold line on a two-dimensional plane of $T_{z}$ and $S_{z}$. The $T-S$ gradient method judges whether the SSD is formed or not by comparing the measurement gradients marked by a point on the plane of $T_{z}$ and $S_{z}$ [14]. As shown in Figure 3, the threshold line divided the plane into two areas: the colored areas above the threshold line and the colorless areas under the threshold line. When all of the gradient measurements are located in the colored areas, this indicates that the SSD is present in the corresponding depth. Conversely, once there is a gradient point below the threshold line, the SSD no longer exists from this depth.

To address the ocean's physical mechanisms governing SSD formation, the colored area can be further subdivided into four areas as follows.

Hydrostatic Duct (Blue Area). Hydrostatic pressure is the dominant factor in duct formation, corresponding to the area enclosed by the threshold line, $S_{z}=-0.016 / \gamma$ and $T_{z}=$ $-0.016 / \beta$.

Haline Duct (Green Area). Positive salinity gradient is the dominant factor, corresponding to the area enclosed by the threshold line, $S_{z}=-0.016 / \gamma$ and $T_{z}=0$.

Thermal Duct (Orange Area). Positive temperature gradient is the dominant factor, corresponding to the area enclosed by the threshold line, $S_{z}=-0.016 / \beta$ and $S_{z}=0$.

Hybrid Duct (Yellow Area). All the factors contribute to the formation of the duct while the effects of temperature and salinity are greater than the static pressure, corresponding to the area located above the hydrostatic duct area and enclosed by $T_{z}=0$ and $S_{z}=0$.

As a result of turbulent mixing, a fine sampled profile may show many points of inflection or drastic slope changes so that the $T-S$ gradient method cannot apply to a profile from CTD. Therefore, this improved method adopts a vertical data smoothing algorithm before diagram analysis. The locally weighted scatter plot smooth analysis (LOWESS) is suitable for preventing erroneous judgments [26]. An essential point is to choose a proper smoothing interval. A short interval cannot filter out point-clouded judgments, whereas a large interval may reduce resolution of depth. Experience has shown that choosing the smoothing interval equal to 5-10 meters gives good results in the NSSCS.

The improved $T-S$ gradient provides a tool of high depth resolution to analyze the relation between the SSD and the physical structure of the upper ocean. The underlying mechanism of whether duct formation occurs may be due to various marine phenomena. Based on the diagram method, the surface acoustic environments under four representative marine phenomena in the diluted area of the NSSCS are presented as follows.

\subsection{Case Study}

Case 1 (cold surge). The data measured on October 3, 2004, at $\mathrm{A} 3\left(22^{\circ} 41^{\prime} \mathrm{N}, 113^{\circ} 58^{\prime} \mathrm{E}\right)$ was selected for the cold surge case (Figure 3 ). During the cruise, a cold surge propagated rapidly southward in the NSSCS. Due to the strong northeast wind, vertical mixing was enhanced and the mixed layer depth increased to $43 \mathrm{~m}$. The cold air took the heat away from 


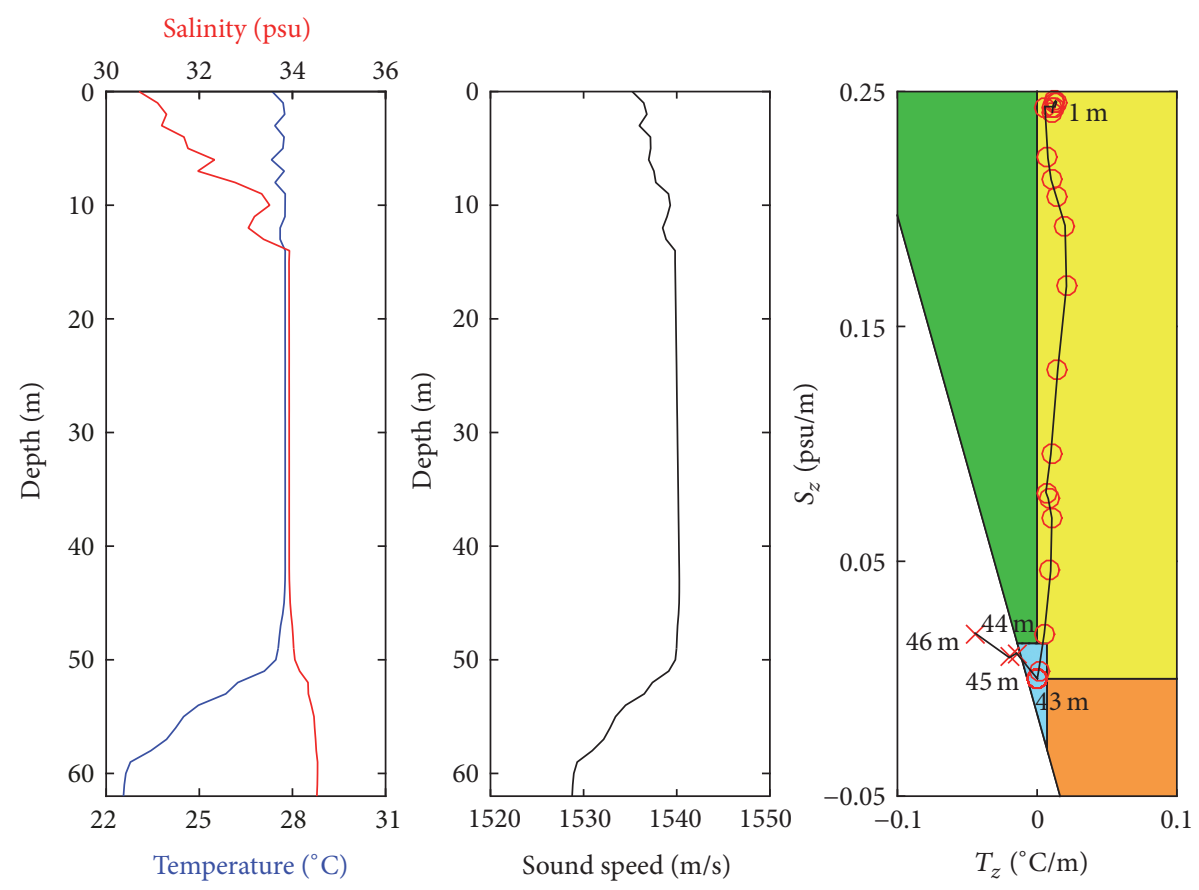

Figure 3: Cold surge case.

the upper ocean, and therefore a slight positive temperature gradient existed in the mixed layer. The diluted water covered the upper $14 \mathrm{~m}$ of water, where the mean salinity gradient was about $0.25 \mathrm{psu} / \mathrm{m}$. The SSD was formed in low-salinity water (Case I).

In the $T$-S gradient diagram, the marks from 1 to $43 \mathrm{~m}$ are above the threshold line, and a duct formed. At different depths, two different kinds of ducts existed simultaneously. From the surface to about $14 \mathrm{~m}$ depth, the marks were located in the zone of the hybrid duct. In the rest of the depth of the mixed layer, both salinity and temperature were nearly constant, indicating that the rest of the marks were located near zero in both axes. That is to say, a hydrostatic duct was formed.

Likewise, most freshening-induced SSD cases in the NSCS were similar to the cold surge case. As the main part of the diluted water was located at the upper $10 \mathrm{~m}$, and with a maximum thickness of not more than $20 \mathrm{~m}$ [27], a hailing duct or hybrid duct was formed in the upper part. Additionally, the mean depth of the mixed layer in the NSSSC in autumn was about $30 \mathrm{~m}$ [28], indicating that there was a hydrostatic duct in the remaining mixed layer without lowsalinity water. When the depth exceeds the lower boundary of the mixed layer, where the thermocline layer is found, a sharp decrease of temperature prevents a positive gradient of sound speed from hydrostatic duct formation.

Case 2 (typhoon genesis). On August 17, Typhoon Nuri formed and then emerged into the South China Sea. The data measured on August 16, 2008, at B2 $\left(22^{\circ} 5^{\prime} \mathrm{N}, 114^{\circ} 56^{\prime} \mathrm{E}\right)$ was selected for the typhoon genesis case (Figure 4). During the period of the typhoon genesis, the measurement site was characterized by sea surface wind with a speed usually less than $3 \mathrm{~m} / \mathrm{s}$ and a warm ocean surface. Consequently, the mixed layer almost disappeared and thermocline layer rose to the sea surface. The SSD was formed in low-salinity water (Case I).

In the $T$ - $S$ gradient diagram, a sharp increase of salinity (about $0.3 \mathrm{psu} / \mathrm{m}$ ) with a relatively small decrease in temperature (about $0.03^{\circ} \mathrm{C} / \mathrm{m}$ ) generated a haline duct from the surface to $7 \mathrm{~m}$. The diluted effect disappeared from $8 \mathrm{~m}$ under the sea surface. As a result, a sharp decrease in temperature (about $0.1^{\circ} \mathrm{C} / \mathrm{m}$ ) with a relatively small increase in salinity (about $0.1 \mathrm{psu} / \mathrm{m}$ ) prevented SSD formation.

Case 3 (offshore upwelling). The data measured on August 16, 2008 , at $\mathrm{C} 1\left(22^{\circ} 41^{\prime} \mathrm{N}, 116^{\circ} 17^{\prime} \mathrm{E}\right)$ was selected for the offshore upwelling case (Figure 5). The Yuedong Upwelling is determined by the results of chemical and biological investigations. The average concentrations of chlorophyll a were $0.15 \mu \mathrm{g} \cdot \mathrm{L}^{-1}$ at the surface of the NSSCS, while the concentration was $2 \mu \mathrm{g} \cdot \mathrm{L}^{-1}$ nearby in $\mathrm{C} 1$ [29]. High chlorophyll a is typically caused by offshore upwelling, bringing nutrients to the surface from the bottom. In addition, the biomarker of coccolithophorids was $32 \%$ of the total biomarks in site $\mathrm{Cl}$ (less than $1 \%$ in other sites of the eastern section) [30]. The high abundance of coccolithophores may be linked with special hydrographic exchange caused by upwelling. The NSCS water mass, which is cold and suitable for coccolithophores, was vertical-mixed with the warm diluted water. The upwelling accelerated vertical mixing and caused a sharp change in both temperature and salinity with sea depth. The SSD was not formed in low-salinity water (Case II). 

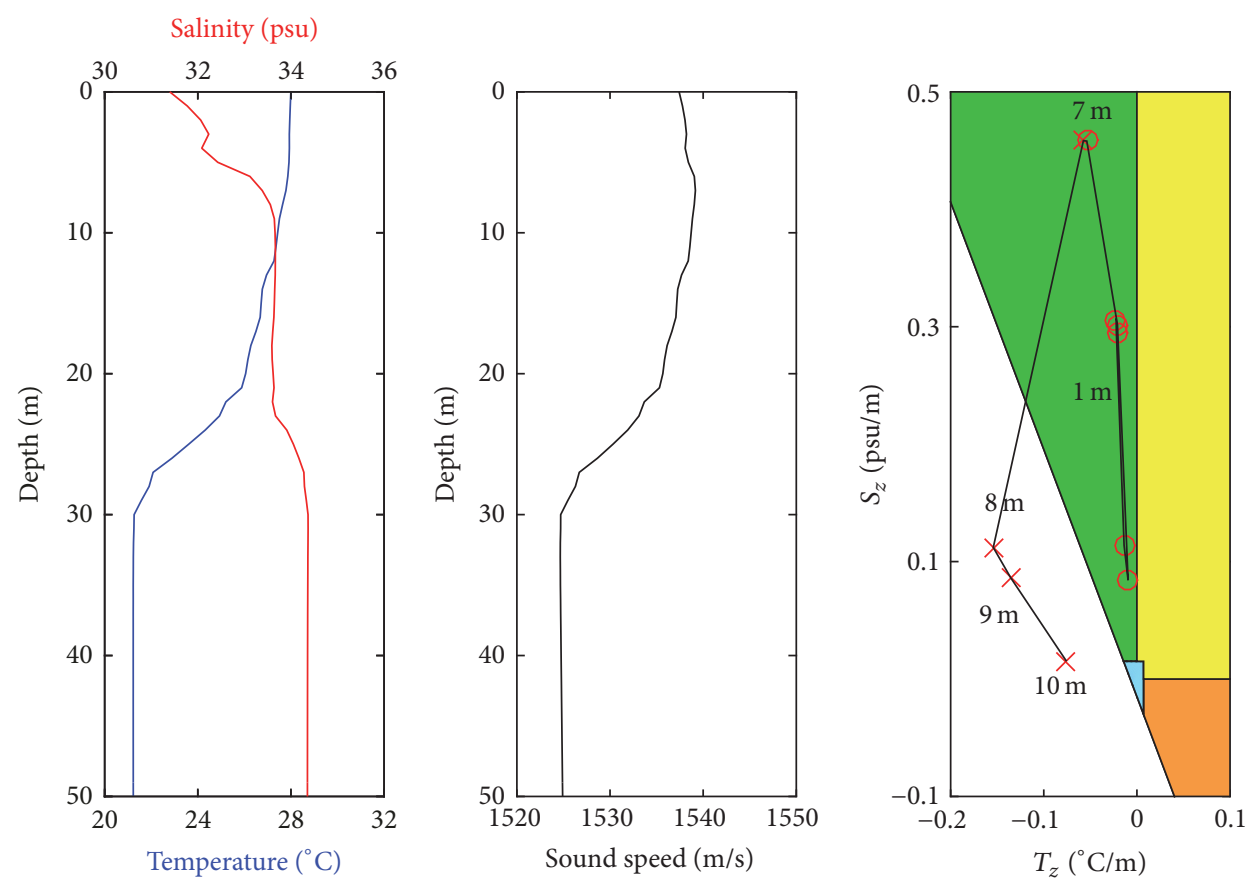

Figure 4: Typhoon genesis case.
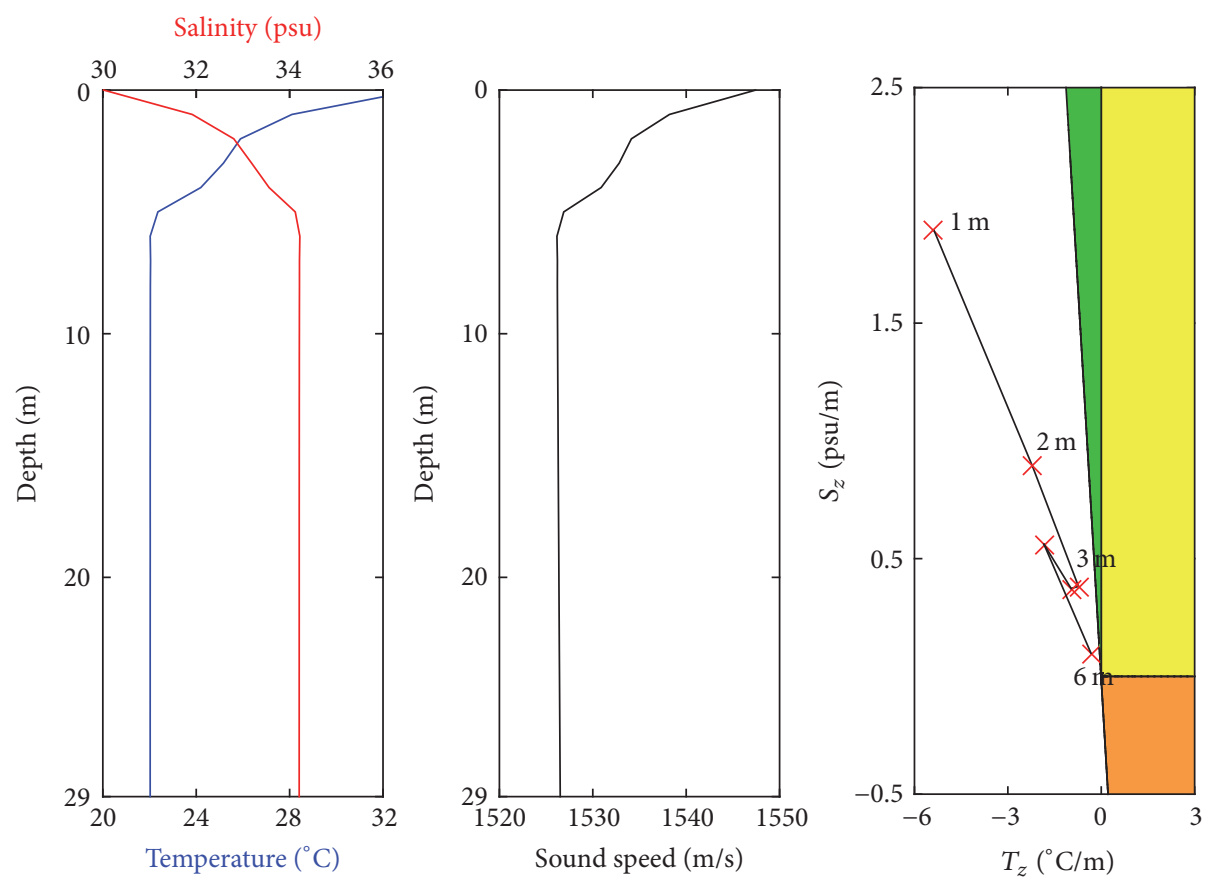

FIgURE 5: Offshore upwelling case.

In the $T$-S gradient diagram, the SSD failed to form due to the large negative $T_{z}$ (about $-2.5^{\circ} \mathrm{C} / \mathrm{m}$ ). Even though the salinity increased drastically with depth in the upper diluted water, temperature can still be a dominant factor in duct formation.

Compared with previous surveys [14], the rate of no haline channel formation in diluted water in the NSSCS (1.6\%) was far less than the rate in East China Sea (57.1\%).
As the isothermal layer in the lower latitudes is relatively more stable, the importance of temperature in haline channel formation is increased with latitude.

Case 4 (low-salinity lens). The data measured on September 19,2009 , at $\mathrm{B} 2\left(22^{\circ} 4^{\prime} \mathrm{N}, 114^{\circ} 56^{\prime} \mathrm{E}\right)$ was selected for the lowsalinity lens case (Figure 6). Low-salinity lens is a mesoscale phenomenon in the NSSCS in the summer. The freshwater 

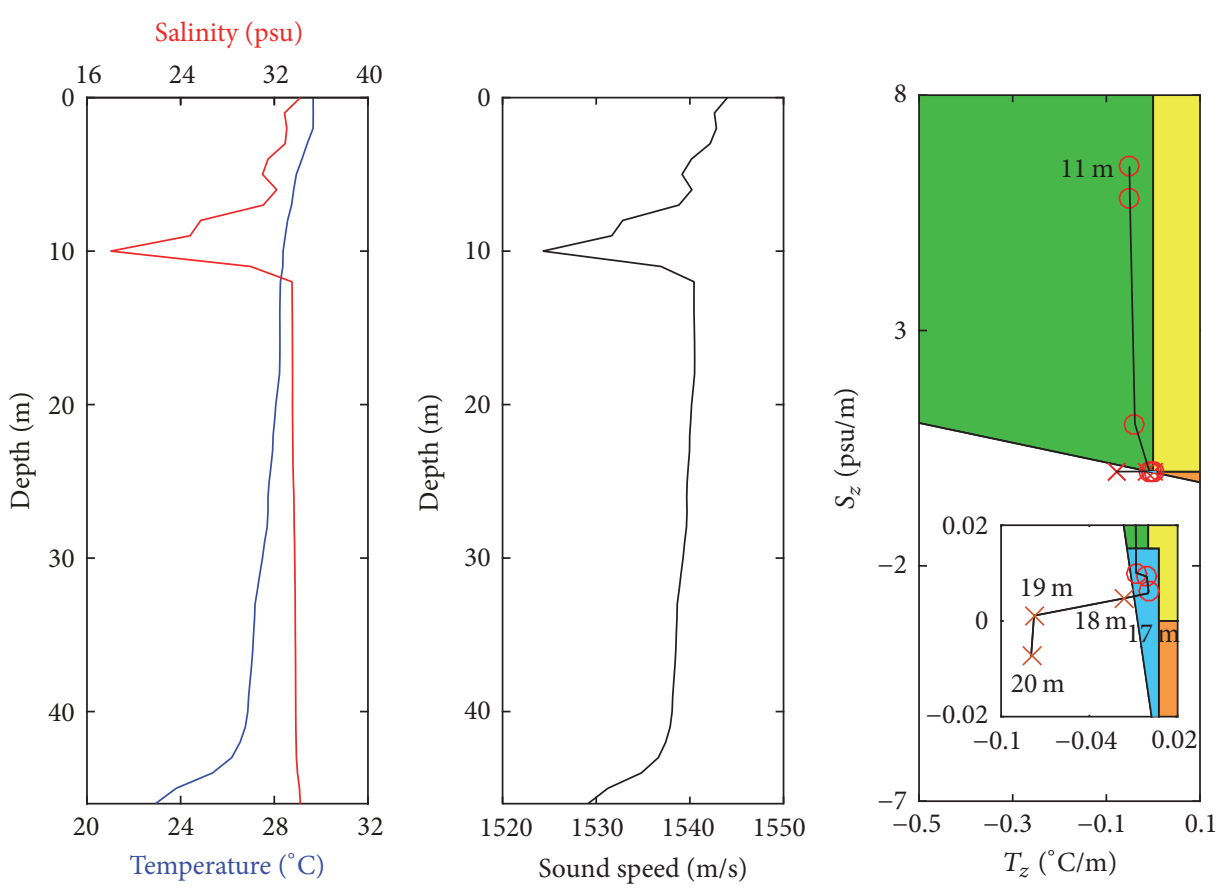

Figure 6: The low-salinity lens case.

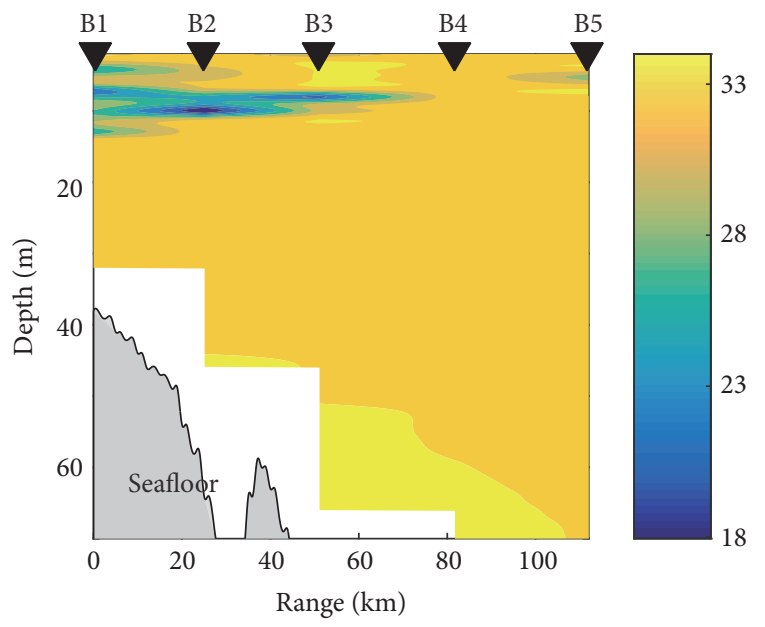

FIgURE 7: Sectional distributions of salinity.

originating from the Pearl River plume was isolated by some dynamic factors. As shown in Figure 7, the relatively isolated low-salinity lens with salinity lower than $32 \mathrm{psu}$ could be found in the upper $20 \mathrm{~m}$ in the sea about $100 \mathrm{~km}$ off the coastline [31]. In the $T$-S gradient diagram, the lens center where the salinity is the lowest can be used as the first mark. Similar to Case 1, the marks from 11 to $17 \mathrm{~m}$ exceed the threshold line. The location of marks indicated that both the haline and hydrostatic duct were present above the thermocline layer. The low-salinity lens case can be considered a special case, in which the center of the duct decreased about $10 \mathrm{~m}$ from the surface. The SSD was formed in low-salinity water (Case I).
TABLE 2: Acoustic characters of duct cases.

\begin{tabular}{lccc}
\hline & Case 1 & Case 2 & Case 4 \\
\hline Duct depth & $43 \mathrm{~m}$ & $7 \mathrm{~m}$ & $6 \mathrm{~m}$ \\
Maximum grazing angle & $4.65^{\circ}$ & $2.73^{\circ}$ & $8.35^{\circ}$ \\
Minimum cutoff frequency & $247 \mathrm{~Hz}$ & $2591 \mathrm{~Hz}$ & $840 \mathrm{~Hz}$ \\
\hline
\end{tabular}

\section{Acoustic Transmission in the SSD}

4.1. Acoustic Characters. Table 2 shows the acoustic characters of the above duct cases. Duct depth, maximum grazing angle, and minimum cutoff frequencies were studied.

Duct depths can be obtained from the $T$-S gradient diagram. The duct depths of Cases 1,2, and 3 were 47, 7, and $6 \mathrm{~m}$, respectively. The analysis of all the CTD profiles showed that temperature structure is a major factor in determining duct depths in the NSSCS. Similar to Cases 1 and 4, the bottom boundary of the mixed layer (or the upper boundary of the thermocline layer) is equal to the duct bottom. In some special cases, like Case 2, the strong gradient of salinity formed the duct and the diluted water layer became the duct. Since the primary aspect of the Pearl River diluted water was located in the upper $10 \mathrm{~m}$, the duct depth of such special cases is usually very shallow.

Energy emitted within the maximum grazing angle will be trapped in the duct, whereas steeper rays leave the duct and propagate via deep bottom-reflected paths. The maximum grazing angle is calculated by [32]

$$
\theta=\sqrt{2 \frac{c(H)-c(S)}{c(S)}},
$$



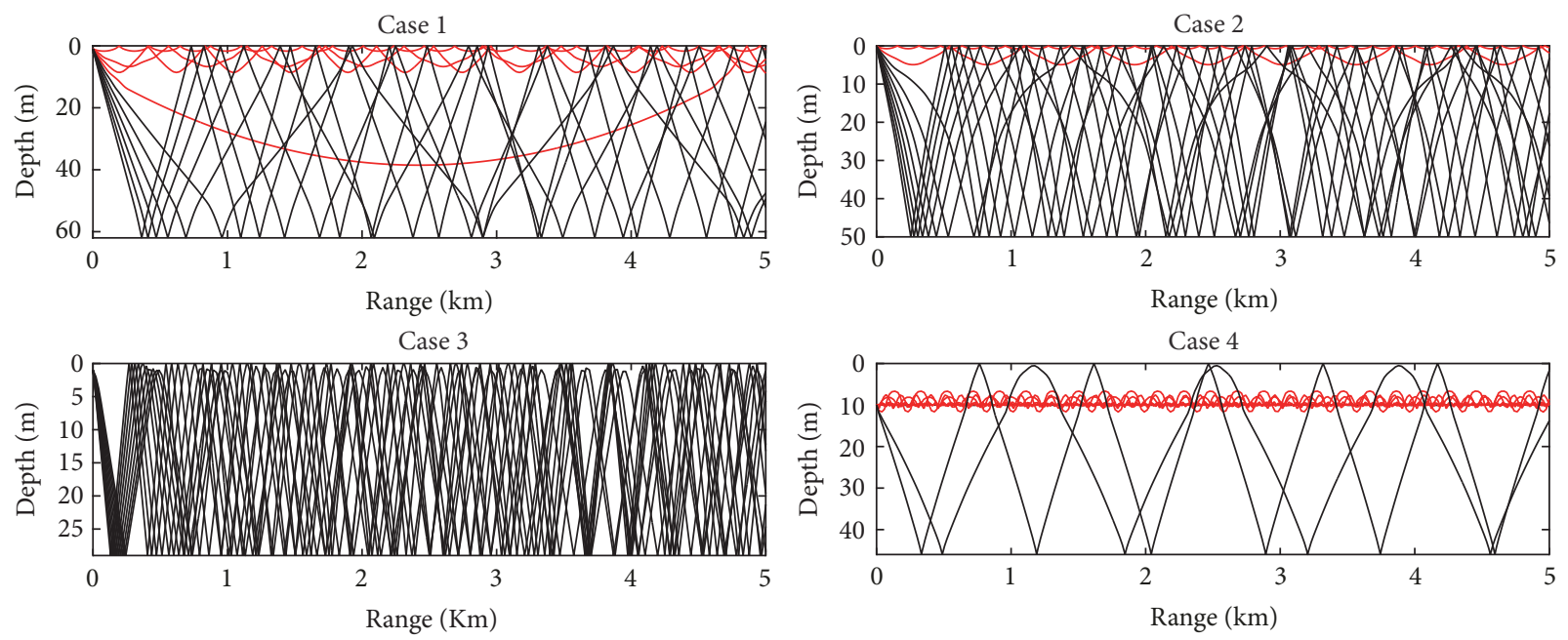

Figure 8: Acoustic ray for different cases.

where $c(H)$ and $c(S)$ are the sound speed on the upper and lower boundary. By introducing the relative mean increment, the rate of sound speed in duct becomes

$$
\alpha=\frac{c(H)-c(S)}{H c(S)} .
$$

A simplified expression for the maximum grazing angle is $\theta=\sqrt{2 H \alpha}$, and it indicates that the maximum grazing angle increases with $H$ and $\alpha$. As shown in the table, the duct depth of Case 1 is about 7 times larger than in Case 4, but the maximum grazing angle is smaller because the increment of sound speed in the duct is small. The diluted water usually results in more effective ducts.

In fact, the duct ceases to trap energy when the acoustic frequency is below the lower bound frequency, called the minimum cutoff frequency. Based on the variable $H$, the approximate formula for the minimum cutoff frequency is given by [33]

$$
f_{c}=\frac{9 c(H)}{8 H \sqrt{8 \alpha H}} .
$$

It is obvious from Table 2 that the minimum cutoff frequency is also dependent on $H$ and $\alpha$. The cutoff frequency of Case 1 is about $10 \%$ of Case 2 due to the deeper duct depth, and the cutoff frequency of Case 3 is much smaller than that of Case 2 because of the steeper gradient of sound speed (Figures 4 and 6). In the NSSCS, shallow ducts $(H<=$ $30 \mathrm{~m}$ ) are most common, but they are effective ducts of much lower frequencies only in diluted areas where the sound speed increment in the upper water column became significant.

4.2. Acoustic Transmission. To illustrate the feature of acoustic transmission in the SSD in the NSSCS, simulations were performed based on the four reprehensive cases. Referring to the bottom of the NSCS [34], the bottom is represented by an infinite halfspace. The sound speed, density, and attenuation coefficients were $1617 \mathrm{~m} / \mathrm{s}, 1,67 \mathrm{~g} / \mathrm{cm}^{3}$, and
$0.1 \mathrm{~dB} / \lambda$, respectively. Based on the ray and normal mode theory, the surface ducts were analyzed in range-independent environments. Referring to the cutoff frequency in Table 2, the source frequency was set to $3000 \mathrm{~Hz}$ for the purpose of duct investigation.

4.2.1. Ray Analysis. The acoustic rays were solved by the beam tracing program BELLHOP [35]. The rays with a take-off angle (toward the bottom) from 1 to $10^{\circ}$ are chosen and the ray step is $1^{\circ}$, such that a total of ten rays were studied. Acoustic source for the first three cases was located near the surface at $1 \mathrm{~m}$, while the source was located at $11 \mathrm{~m}(1 \mathrm{~m}$ below the duct axis) in Case 4 . The acoustic rays for the above four cases are shown in Figure 8. The rays trapped in the duct are plotted with a red line for ease of distinction.

The number of rays trapped in the duct for different cases was $4,2,0$, and 8 , in full agreement with the calculation results in Table 2. From this data, it can be seen that the angle range of trapped rays increases with increases in the duct depth and refractivity. In the diluted areas of the NSSCS, the diluted layers of less than 10 meters are usually more effective at producing a duct than a mixed layer in excess of 40 meters. Moreover, the acoustic rays are more dense in the haline duct due to stronger refraction; that is, there is a stronger concentration of energy. As shown in the ray diagram of Case 1, the energy propagated in the duct is mainly in the haline channel which accounts for only one-third of the duct depth. For the case of no acoustic duct formation, the energy distribution was relatively uniform.

4.2.2. Mode Analysis. The mode amplitude was solved by the normal mode program KRAKEN [36] and the first 20 mode amplitudes of Case 1 are shown in Figure 9.

The mode amplitude of the lower mode was shown to be more depth-dependent, whereas the energy distribution of the higher mode was relatively uniform with depth. In the SSD transmission, only a fraction of lower modes was effective and their amplitudes were strongly depth-dependent. For 

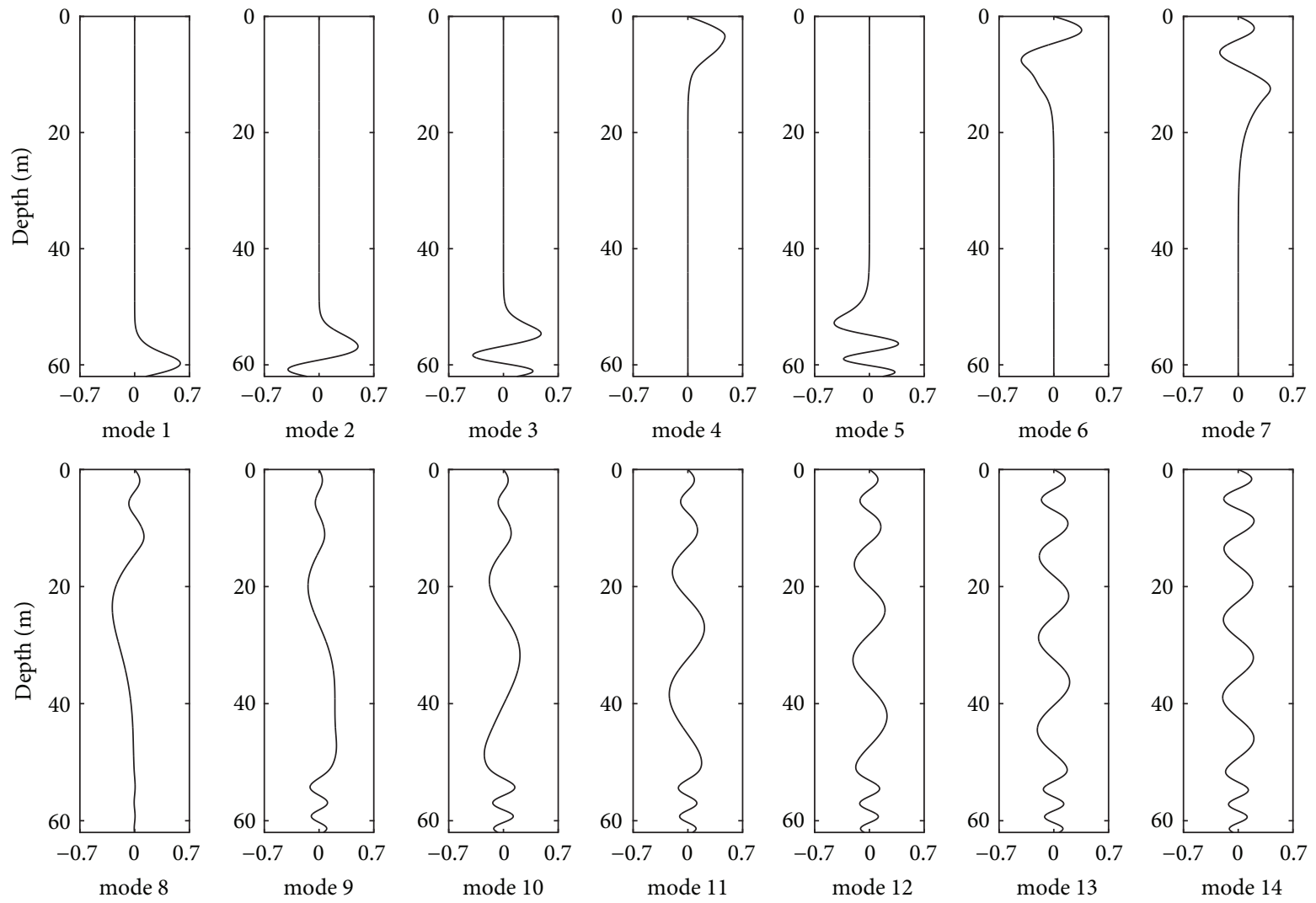

Figure 9: Mode amplitudes for Case 1.

example, the first three modes of large amplitudes could not propagate in the surface duct owing to zero amplitude in the surface duct. The fourth mode, which had the largest amplitude in the duct, became one of the dominant modes. Additionally, a remarkable amplitude was generated in the fourth mode when the source was located at $3.4 \mathrm{~m}$, but the amplitude was nearly zero in the remaining depth intervals of the duct. These data indicate that an appropriate source depth can improve the performance of sound transmission in SSD.

4.2.3. Transmission Loss Analysis. The transmission loss (TL) was computed by KRAKEN for each case. To highlight the duct effect, the sound source was located at a depth where the amplitude of the dominant mode was a peak in the upper water, that is, $3.4 \mathrm{~m}, 3.7 \mathrm{~m}, 2.9 \mathrm{~m}$, and $9.8 \mathrm{~m}$ for the following cases. The TLs for the four cases are shown in Figure 10.

Duct propagation was observed in Cases 1, 2, and 4, while TL fluctuations with range and depth were observed in Case 3. Some points can be drawn from Figure 10. For Case 1, the haline duct was a more effective duct than the hydrostatic duct. Although the depth of the whole duct was $43 \mathrm{~m}$, the energy was mainly trapped in the diluted layer of $14 \mathrm{~m}$. For Case 2, the duct propagation was present, but it was relatively weak. As the source frequency is only a little higher than the cutoff frequency, an energy leakage was observed. For Case 3, there was no duct; the energy was relatively uniform due to the bottom and surface reflection. For Case 4, the duct formed by a large sound speed gradient in the low-salinity lens was even more efficient than other ducts from $10 \mathrm{~km}$ away from the source.

For a quantitative description of duct propagation, horizontal TLs were calculated, as shown in Figure 11. Depthaverage TLs were computed with a range in the duct (1-10 m for Case 3) and the 10-meter layer under the duct. In general, the average TLs in the ducts were less than that which was observed out of the ducts. When the duct was not formed, TLs in the two layers were similar to Case 3. The difference in TLs in Case 1 was not as large as in Case 3. To show the energy distribution, the average TL in the upper haline duct was also calculated and plotted in the blue line. It can be seen that the TL in the upper haline duct had more effective propagation. This conclusion is consistent with Figure 10. In Case 2, although the TL in the duct showed a greater oscillation, the average TL in the duct was less than that observed out of the duct for most of the ranges. If the source frequency increased, then the duct effect may be more effective. In Case 4, the TLs in and out of the duct are very different. In this case, the lowsalinity lens became a very efficient energy channel.

\section{Discussion and Conclusion}

Although the SSD is different from the sonar duct in spatiotemporal variability, it is still an excellent waveguide for long-range propagation. For the diluted area in the NSSCS, it is the only effective acoustic duct. Knowing the formation and acoustic characteristics of the SSD can improve the 

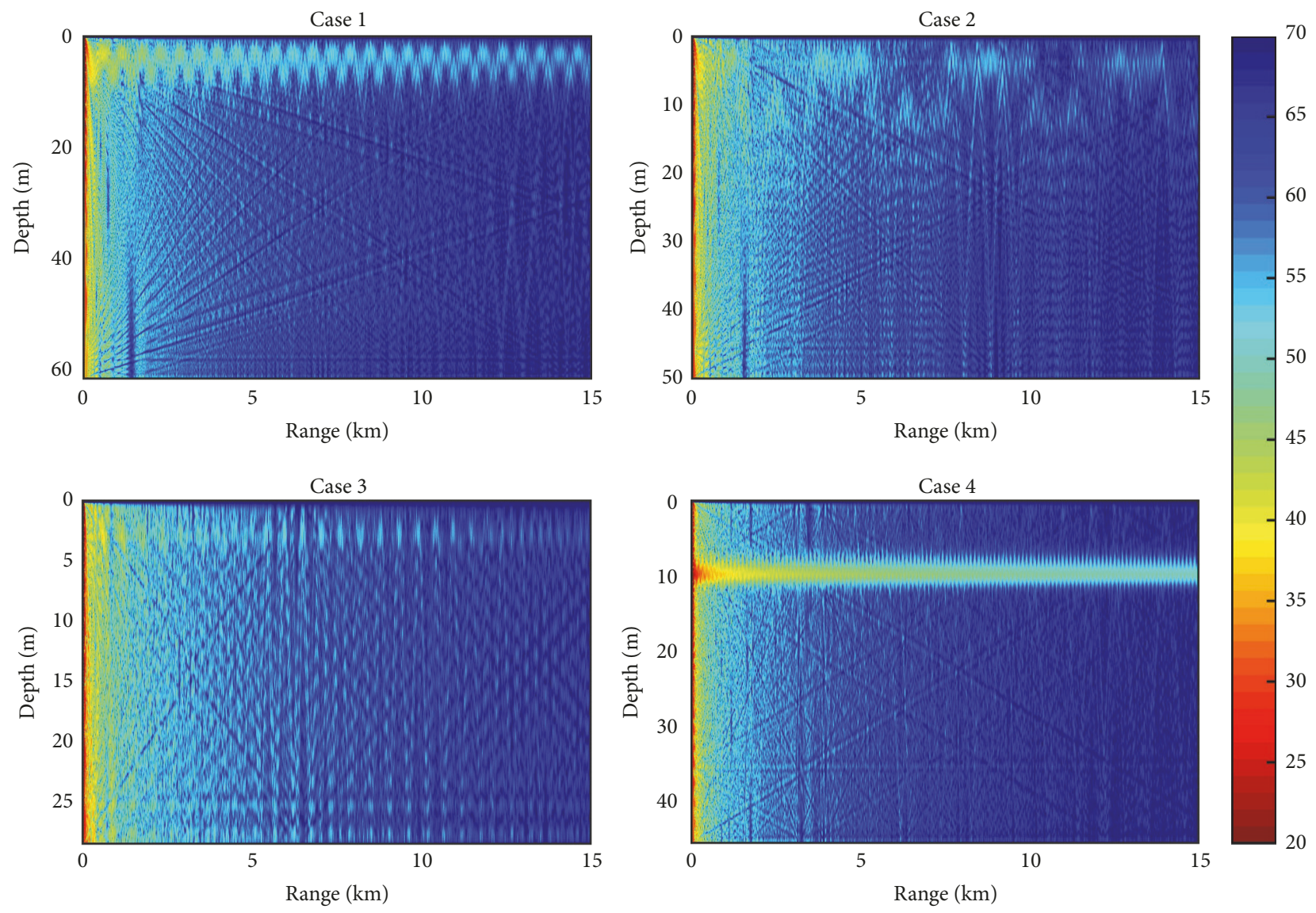

FIgURE 10: TLs for different cases.

performance of near-surface sonar in both naval and fishing applications.

In situ CTD observations confirmed that surface ducts are almost universal in the NSSCS during autumn, especially in the diluted area. However, various marine phenomena contribute to the complicated relationship between duct formation, salinity, and temperature gradient. For example, the SSD cannot be formed due to a large negative temperature gradient in the offshore upwelling area, although the salinity gradient shows a large positive value. Even if the SSD formed, it is difficult to ascertain the physical mechanisms that govern a waveguide formation. Therefore, an improved $T-S$ gradient method is proposed in this paper. The first advantage of the improved method is that it enables the analysis of fine sampled data. Another advantage is that there are four types of ducts to evaluate the contribution of salinity, temperature, and pressure.

Based on the $T-S$ gradient method, four CTD profiles were analyzed. Results are summarized as follows:

(1) In the presence of the mixed layer, salinity became a dominant cause of duct formation for the diluted area. In the absence of the mixed layer, the formation of the surface duct was affected by large gradients of temperature and salinity; the relative values between them determined whether the duct formed or not.
(2) In the NSSCS, a duct may consist of two different types of ducts at different depths. In general, the upper diluted duct had a larger value of the sound speed gradient than the lower hydrostatic duct. The upper duct was more conducive to long-range propagation.

(3) Marine phenomena, such as river plume, cold surge, typhoon, upwelling, and low-salinity lens, can strongly affect the oceanographic parameters in the upper ocean. This observation raised an interesting question as to whether the duct exists. The $T-S$ gradient diagram proved to be a useful tool to investigate the surface duct formation process.

(4) Duct depth is an important characteristic that affects the performance of sound propagation in the duct. As the thinness of the diluted layer is usually no more than 10 meters, the duct depth of a fresheninginduced duct is small. However, large salinity gradients significantly increase the maximum grazing angle and decrease the cutoff frequency, resulting in a more effective duct. For example, as shown in Figure 11, the average TL in the duct of the low-salinity lens is only $60 \mathrm{~dB}$ at $15 \mathrm{~km}$. The difference between within and outside of the channel is about $10 \mathrm{~dB}$.

It should be noted that the results presented in this paper are based on a status of fixed source depth and frequency. 

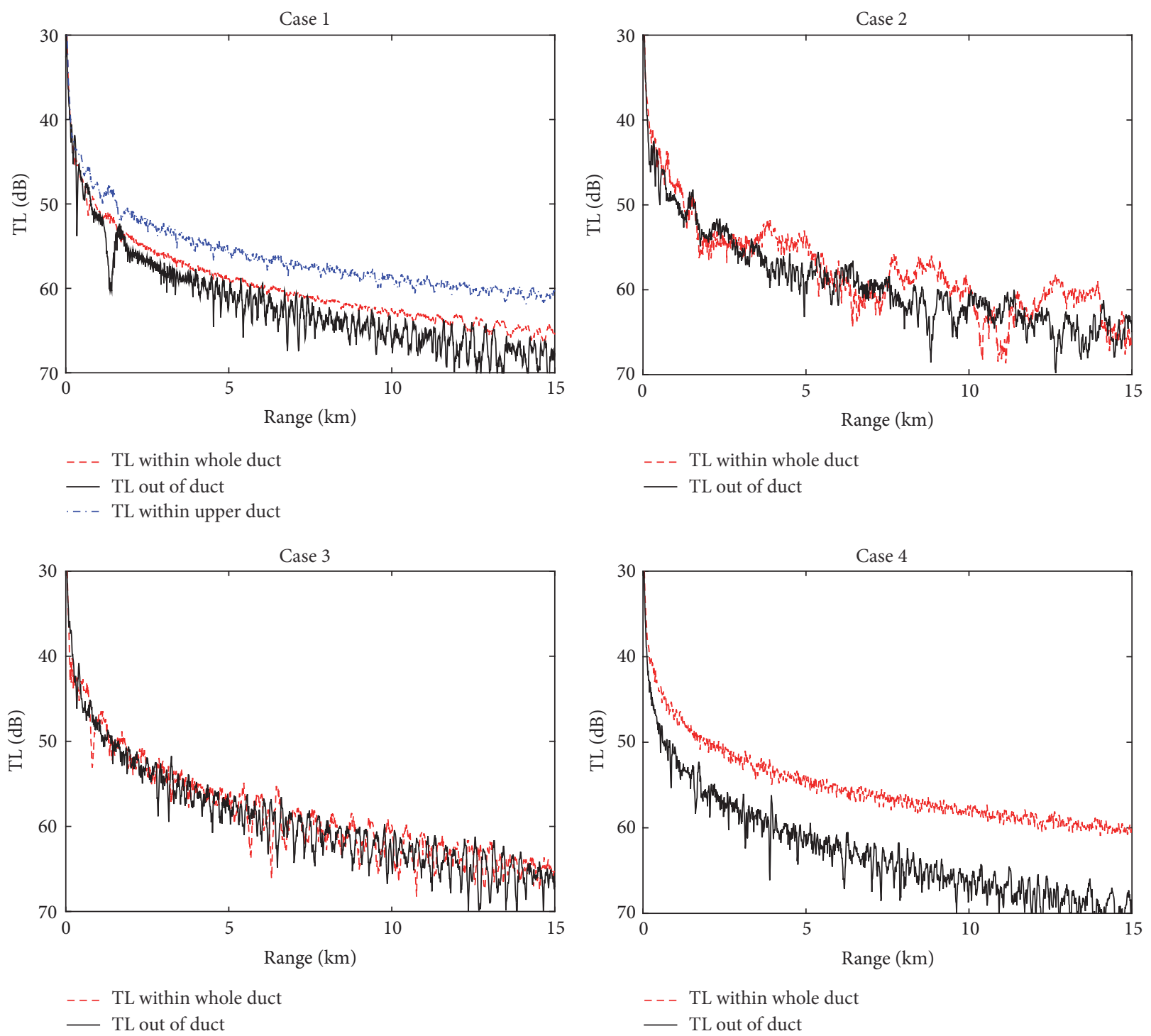

FIgURE 11: Depth-average TLs for different cases.

Some results present here, such as Figures 8 and 9, strongly suggest that frequency and sound depth should be carefully considered in the investigation of sound propagation. Further systematic study is necessary to ascertain the complicated relationship between the frequency, source depth, and other duct characteristics. However, since this study analyzed the contributions of various factors to duct formation in a low-salinity environment, fixed source depth and frequency were enough to explain the results of different formation mechanisms. The above conclusions are generally useful for the sonar applications in the NSSCS.

\section{Conflicts of Interest}

The authors declare that there are no conflicts of interest regarding the publication of this paper.

\section{Acknowledgments}

This study is supported by the National Natural Science Foundation of China (41406041), the Natural Science Foundation of Guangdong Province (2014A030310256), and the Project of Enhancing School With Innovation of Guangdong Ocean University (GDOU2016050246). The authors would like to acknowledge the data support from "South China Sea and Adjacent Seas Data Center, National Earth System Science Data Sharing Infrastructure, National Science \& Technology Infrastructure of China (http://ocean.geodata.cn)."

\section{References}

[1] L.-G. Lü, H.-X. Chen, and Y.-L. Yuan, "Spatial and temporal variations of sound speed at the PN section," Journal of Oceanography, vol. 60, no. 4, pp. 673-679, 2004. 
[2] X. Zhang, Y. Zhang, and J. Zhang, "The effect of ocean mixedlayer structure on acoustic propagation in a surface duct environment," Acta Oceanologica Sinica, vol. 34, no. 1, pp. 7989, 2012.

[3] L. Zeng, W. Timothy Liu, H. Xue, P. Xiu, and D. Wang, "Freshening in the South China Sea during 2012 revealed by Aquarius and in situ data," Journal of Geophysical Research: Oceans, vol. 119, no. 12, pp. 8296-8314, 2014.

[4] S. E. Dosso and N. R. Chapman, "Acoustic propagation in a shallow sound channel in the northeast pacific ocean," The Journal of the Acoustical Society of America, vol. 75, no. 2, pp. 413-418, 1984.

[5] H. G. Schneider, R. Thiele, and P. C. Wille, "Measurement of sound absorption in low salinity water of the baltic sea," The Journal of the Acoustical Society of America, vol. 77, no. 4, pp. 1409-1412, 1985.

[6] M. Schulkin, "Surface-coupled losses in surface sound channels," The Journal of the Acoustical Society of America, vol. 44, no. 4, pp. 1152-1154, 1968.

[7] W. F. Baker, "New formula for calculating acoustic propagation loss in a surface duct in the sea," The Journal of the Acoustical Society of America, vol. 57, no. 5, pp. 1198-1200, 1975.

[8] R. H. Zhang, "Normal mode acoustic field in a shallow-water surface channel," Chinese Journal of Physics, vol. 24, no. 3, pp. 506-510, 1975.

[9] D. E. Weston, C. G. Esmond, and A. Ferris, "The duct leakage relation for the surface sound channel," The Journal of the Acoustical Society of America, vol. 89, no. 1, pp. 156-164, 1991.

[10] R. Duan, K.-D. Yang, and Y.-L. Ma, "Investigation of long-range sound propagation in surface ducts," Chinese Physics B, vol. 22, no. 12, Article ID 124301, 2013.

[11] N. P. Bulgakov, Y. V. Artamonov, P. D. Lomakin, and V. N. Cheremin, "Acoustic properties of surface water masses in the tropical atlantic and their seasonal variability," Soviet Journal of Physical Oceanography, vol. 3, no. 2, pp. 141-147, 1992.

[12] N. P. Pulgakov and P. D. Lomakin, "Acoustic characteristics of seawater in the area of the coastal discharge front off the guinean shore," Physical Oceanography, vol. 5, no. 2, pp. 141-147, 1994.

[13] J. Kim, H. Kim, and D. Paeng, "Analysis of haline channel formed in the East China Sea and the Atlantic Ocean using the T-S gradient diagram," Journal of the Korean Society of Marine Engineering, vol. 38, no. 2, pp. 208-216, 2014.

[14] J. Kim, H. Kim, D.-G. Paeng, T.-H. Bok, and J. Lee, "Lowsalinity-induced surface sound channel in the western sea of Jeju Island during summer," The Journal of the Acoustical Society of America, vol. 137, no. 3, pp. 1576-1585, 2015.

[15] S.-P. Xie, Q. Xie, D. Wang, and W. T. Liu, "Summer upwelling in the South China Sea and its role in regional climate variations," Journal of Geophysical Research: Oceans, vol. 108, no. C8, Article ID 3261, 2003.

[16] L. Dong, J. Su, L. Wong, Z. Cao, and J.-C. Chen, "Seasonal variation and dynamics of the pearl river plume," Continental Shelf Research, vol. 24, no. 16, pp. 1761-1777, 2004.

[17] S. Ou, H. Zhang, D.-X. Wang, and J. He, "Horizontal characteristics of buoyant plume off the Pearl River Estuary during summer," Journal of Coastal Research, vol. 23, no. 1, pp. 652-657, 2007.

[18] T. Zu and J. Gan, "A numerical study of coupled estuaryshelf circulation around the pearl river estuary during summer: responses to variable winds, tides and river discharge," DeepSea Research Part II: Topical Studies in Oceanography, vol. 117, pp. 53-64, 2013.
[19] X. Zhang, Y. G. Zhang, and J. X. Zhang, "The effect of ocean mixed-layer structure on acoustic propagation in a surface duct environment," Acta Oceanologica Sinica, vol. 34, no. 1, pp. 79-89, 2012.

[20] L. Jia, K. Yang, and B. Lei, "Research on the temporal-spatial distributions and the physical mechanisms for the sound speed profiles in north-central indian ocean," Chinese Journal of physics, vol. 61, no. 8, pp. 282-299, 2012.

[21] L. Yang, D. Wang, J. Huang et al., "Toward a mesoscale hydrological and marine meteorological observation network in the South China Sea," Bulletin of the American Meteorological Society, vol. 96, no. 7, pp. 1117-1135, 2015.

[22] L. Zeng, Q. Wang, Q. Xie et al., "Hydrographic field investigations in the Northern South China Sea by open cruises during 2004-2013," Chinese Science Bulletin, vol. 60, no. 6, pp. 607-615, 2015.

[23] H. Medwin, "Speed of sound in water: A simple equation for realistic parameters," The Journal of the Acoustical Society of America, vol. 58, no. 6, pp. 1318-1319, 1975.

[24] H. L. Mao, Z. J. Gan, and S. F. Lan, "A preliminary study of the Yangtze diluted water and its mixing processes," Oceanologia et Limnologia Sinica, vol. 5, no. 3, pp. 183-206, 1963.

[25] L. A. Wong, J. C. Chen, and H. Xue, "A model study of the circulation in the Pearl River Estuary (PRE) and its adjacent coastal waters: 1 . Simulations and comparison with observations," Journal of Geophysical Research: Atmospheres, vol. 108, no. C5, pp. 249-260, 2003.

[26] W. S. Cleveland, "Robust locally weighted regression and smoothing scatterplots," Journal of the American Statistical Association, vol. 74, no. 368, pp. 829-836, 1979.

[27] Y. Yang, L. Rx, and P. L. Zhu, "Seasonal variation of the pearl river diluted water and its dynamical cause," Marine Science Bulletin, vol. 33, no. 1, pp. 36-44, 2014.

[28] W. J. Wang, Y. D. Liu, and Q. I. Chen, Classification and Seasonal Variability of The Sound Velocity Spring Layer in The South China Sea, Marine Sciences, 2014.

[29] Ke. Zx, L. M. Huang, and Y. H. Tan, "Spatial distribution of chlorophyll a and its relationships with environmental factors in northern south china sea in late summer 2008," Journal of Tropical Oceanography, vol. 32, no. 4, pp. 51-57, 2013.

[30] L. Li, J. Liu, J. He, and H. Wang, "Factors affecting the abundance and community structure of the phytoplankton in northern South China Sea in the summer of 2008: a biomarker study," Chinese Science Bulletin, vol. 59, no. 10, pp. 981-991, 2014.

[31] C. S. Jing, J. Huang, and X. G. Guo, "Low salinity lenses in the northeastern shelf of the south china sea and their possible formation mechanism in summer, 2002," Journal of Applied Oceanography, vol. 32, no. 2, pp. 148-155, 2013.

[32] L. M. Brekhovskikh and Y. P. Lysanov, Fundamentals of Ocean Acoustics, Springer, New York, NY, USA, 1982

[33] B. S. Liu and J. Y. Lei, Principles of Underwater Sound, Harbin Engineering University Press, Harbin, China, 2010.

[34] L. He, "Inversion for sound speed profiles in the northern of south china sea," Scientia Sinica, vol. 41, no. 1, pp. 49-57, 2011.

[35] M. B. Porter, “The bellhop manual and user's guide: preliminary draft," http://oalib.hlsresearch.com/Rays/index.html, 2011.

[36] M. B. Porter, "The kraken normal mode program," http:// oalib.hlsresearch.com/Modes/AcousticsToolbox/manual_html/ kraken.html, 1992. 


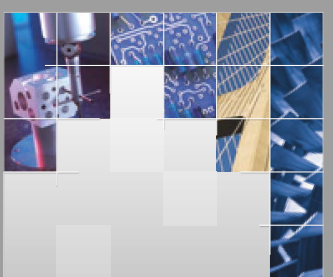

\section{Enfincering}
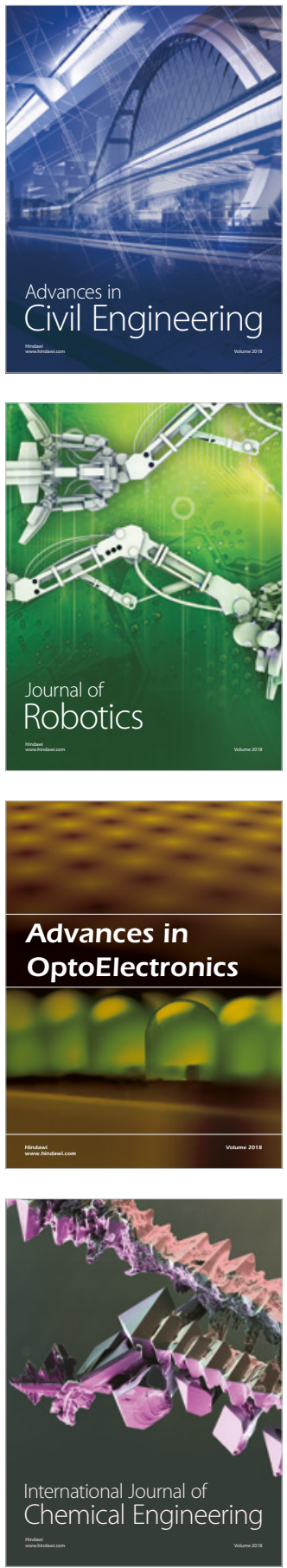

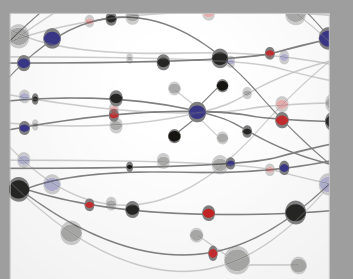

\section{Rotating \\ Machinery}

The Scientific World Journal

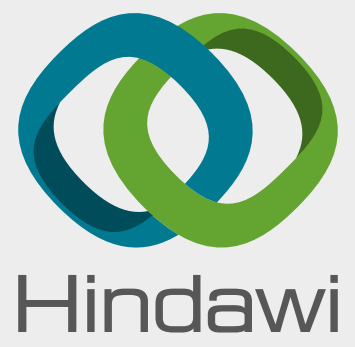

Submit your manuscripts at

www.hindawi.com
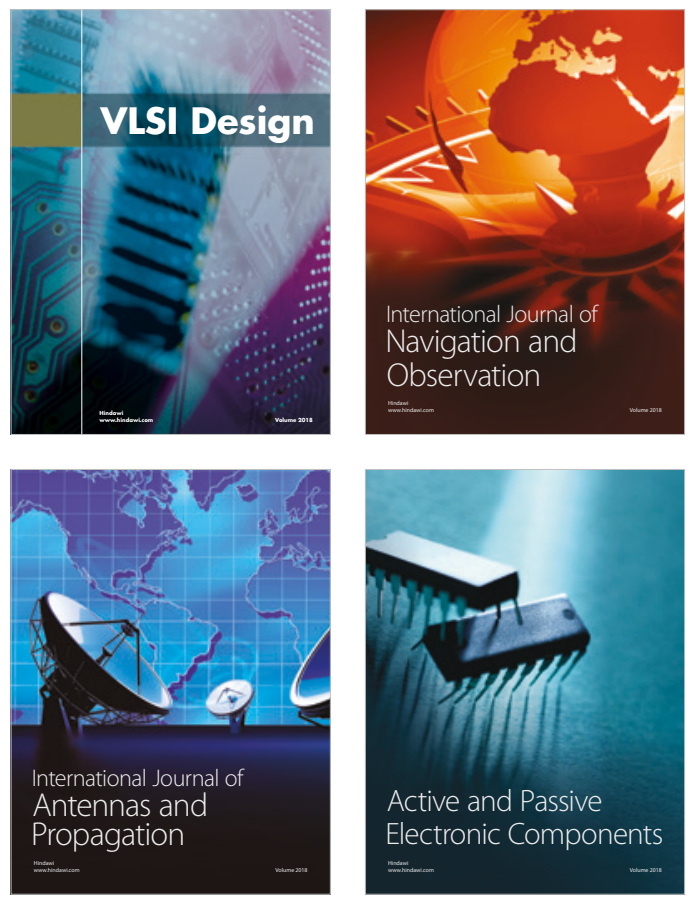
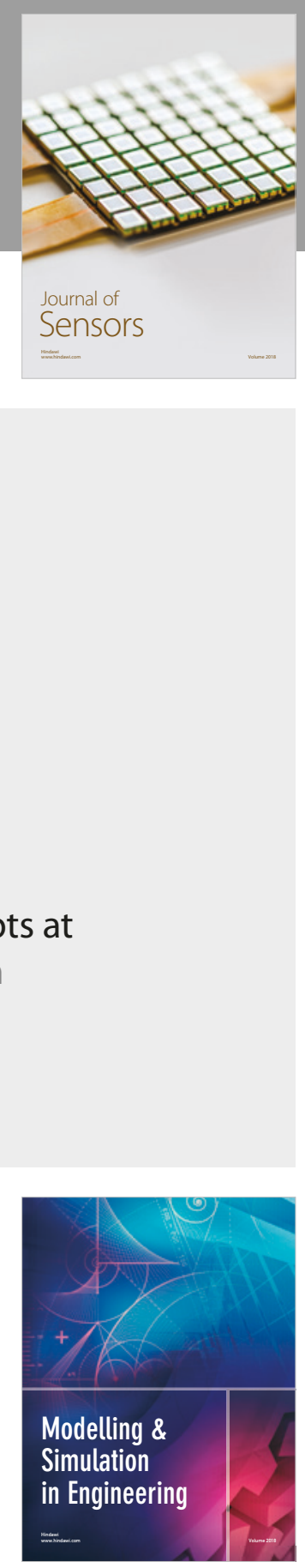

\section{Advances \\ Multimedia}
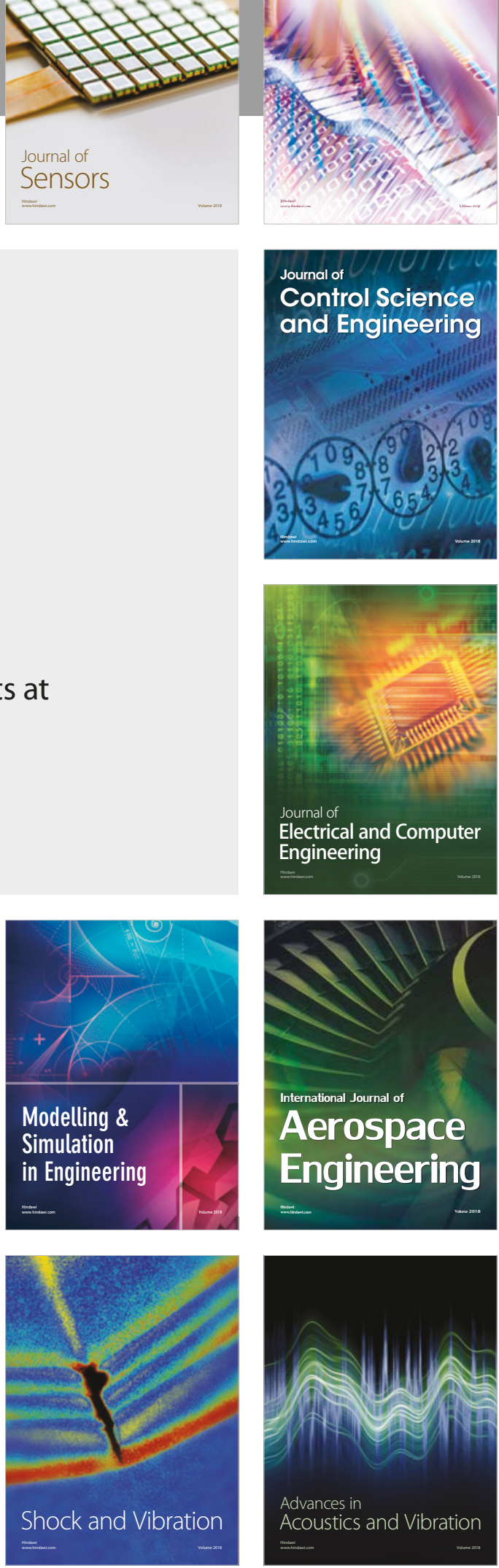